\title{
Exploring Canadian Integration through Critical Discourse Analysis of English Language Lesson Plans for Immigrant Learners
}

\author{
Marianne Barker \\ McGill University
}

\begin{abstract}
The Canadian government implemented the Language Instruction for Newcomers to Canada (LINC) program to help immigrants integrate into Canada. However, research indicates that the LINC program fails to achieve its integrative goals. Using Fairclough's analytical concepts of genre, discourse and style, this article closely examines a unit of LINC lesson plans to understand how they advance an understanding integration among classroom stakeholders (Canadian teachers and immigrant students). The analysis reveals that the LINC curriculum proliferates inequality between Canadians and newcomers by fostering an assimilative orientation that subjugates immigrants as problematic Others. Immigrants are expected to conform to dominant Canadian ways of being and ways using language. This article calls for a rethinking of integration by identifying possibilities for resistance that could shift immigrants' positioning and reduce discrimination. This could occur through better recognizing bias and dominance, and through acknowledging and validating newcomers' ways of speaking and interacting.
\end{abstract}

\section{Résumé}

Créé par le Gouvernement canadien, le Cours de Langue pour les Immigrants au Canada (CLIC - LINC en anglais) a pour but de faciliter l'intégration des immigrants établis au Canada. Cependent, des résultats de recherche signalent que le programme CLIC n'atteint pas ses buts d'intégration des immigrants. Utilisant les concepts analytiques de genre, de discours et de style de Fairclough, cet article examine de près un module de plusieurs plans de cours CLIC afin de comprendre comment ces modules visent à promouvoir l'intégration chez les parties prenantes (enseignants canadiens et étudiants immigrants) en classe. La problématique soulevée par mon analyse souligne que le programme d'études CLIC prolifère l'inégalité entre les Canadiens et les nouveaux arrivants en favorisant une orientation assimilative qui subjugue les nouveaux arrivants. On s'attend à ce que les nouveaux arrivants se conforment aux façons d'être dominantes du Canada et aux façons d'utiliser la langue. Cet article nous invite à repenser l'intégration en identifiant les possibilités de résistance qui pourraient changer le positionnement des nouveaux arrivants et réduire la discrimination. Cela pourrait se produire en identifiant les préjugés et la dominance, ainsi qu'en reconnaissant et en validant les façons de parler et d'intéragir des nouveaux arrivants. 


\title{
Exploring Canadian Integration through Critical Discourse Analysis of English Language Lesson Plans for Immigrant Learners
}

\author{
A Social Problem: Calling Canadian Multiculturalism into Question
}

The ideals of Canadian multiculturalism are under unprecedented strain in the current era of right-wing xenophobic populism. While massive numbers of immigrants are admitted into Canada to support the Canadian economy and balance an ageing population (IRC Canada, 2017), immigrants continue to face major obstacles to social and professional integration, including unemployment, low incomes, and discrimination (Cardozo \& Pendakur, 2008). Attempting to respond to these obstacles, the Canadian government implemented the Language Instruction for Newcomers to Canada (LINC) program. This government-funded English language program is offered free to adult immigrants and aims to help "newcomers integrate into Canada and their communities" both socially and professionally (ARCHIVED - backgrounder - language instruction for newcomers to Canada [LINC] program, 2013). However, research has shown that the program falls short of its integrative goals. Ricento et al. (2008) found that LINC participants felt the program was inadequate in helping them achieve their academic and career goals. Moreover, the LINC program promotes and teaches "Canadian culture" and a "Canadian way of using language", which reflects problematic assimilative aims rather than cultivating a sense of belonging in Canada (Gibb, 2009; Guo, 2015; Haque, 2017).

This assimilative orientation towards immigrants in Canada is pervasive and historical. Although Canada is internationally esteemed for its integration of immigrants' unique cultural backgrounds within a diverse multicultural society (Bloemraad, 2016), as of 2016, $68 \%$ of Canadians hold assimilationist attitudes towards immigrants (Kurl, 2016; Li, 2003). This assimilationist expectation that newcomers should change to conform to Canadian norms and values is partly due to Canada's official "multiculturalism within a bilingual framework" policy. This policy has proliferated structural inequalities for minorities and nurtured hierarchical conceptions of language and culture that advance a bicultural English-French society (Day, 2000; Haque, 2012). Assimilative discourses reflect deficit ideologies and ongoing democratic racism, which is the superficial nominal acceptance of minorities while simultaneously inhibiting their rights (Guo, 2015). Briefly, the expectation that newcomers conform or assimilate to Canadian standards outweighs and obscures integration and multiculturalism in Canadian policy, making them nothing more than ideological.

\section{Discourses of Immigration in Canada}

Much of the recent research concerned with equality for newcomers in Canada has focused on discourses within policy at federal and provincial levels (Joshee, 2009); citizenship guides for newcomers (Gulliver, 2018; Joyce, 2014; Pashby, et al., 2013); classroom materials and textbooks used in language classes for immigrant learners (Gulliver \& Thurrell, 2016); and on the use of critical pedagogies in language classes for immigrants (Chun, 2016; Guo, 2009). Many of these works build on van Dijk's (1992) theorization of denials of racism. van Dijk suggests that a defining property of modern racism is its denial: 
If tolerance is promoted as a national myth... It is much more difficult for minority groups to challenge remaining inequalities, to take unified action and to gain credibility and support among the (white) dominant group. Indeed, they may be seen as oversensitive, exaggerating or over demanding (p. 96).

Indeed, in Canada, integration is articulated as a two-way process where both newcomers and Canadian society make mutual adjustments (Guo, 2013; Li, 2003). Yet, it is primarily the newcomer's responsibility to overcome barriers. Gulliver's (2018) analysis of Canadian citizenship guides shows that when Canada is framed as multicultural, it "pre-emptively [denies] that a discourse could be both Canadian and racist" (p. 70). Discourses of multiculturalism excuse Canadians from considering that inequality is a systemic problem in Canadian society (Augoustinos \& Every, 2010; Pashby et al., 2013).

This discursive racism extends into the LINC program, where a direct link is forged between acquiring language and "being Canadian". Haque (2017) posits that language training programs in Canada position language as a "skill, commodity and deficit" (p. 104). It is the immigrant's role to invest in language learning to "become more Canadian". In an analysis of language textbooks for immigrants, Gulliver and Thurrell (2016) suggest that the materials are "sites through which powerful and dominant discourses enter the classroom and are introduced to refugees and immigrants" (p. 45). They point out that such texts require close attention because discourses become more influential when they are obligatory, authoritative, and unchallenged. Gulliver and Thurrell importantly note that the texts fail to critically examine how white dominance shapes institutions and language use in Canada, meaning that marked identities remain invisibilized. Immigrants internalize these colonial discourses promoted through policy and advanced through language curriculum, texts and administration, and immigrants are encouraged to take responsibility to change themselves to make themselves more presentable or employable by reducing their accent or changing their name (Guo, 2009). Discourses in Canadian textbooks present Canada and Canadians positively, even as the redeemer while positioning immigrants as passive, powerless, lacking cultural understanding and needing to be educated.

Similarly, Fleming's (2015) analysis of the LINC program's assessment tool, the Canadian Language Benchmarks (CLB), demonstrates that the CLB portrays the ideal Canadian citizen as a passive and obedient worker and consumer. Fleming notes there is only one reference to active citizenship (voting) at the highest level of the CLB, indicating that "opinions not expressed in English [have] little value in terms of Canadian citizenship" (p. 47). This constitutes a hierarchy of citizenship according to language proficiency. Evaluating citizenship based on language ability is an ideology that justifies and propagates continued domination and exploitation. Increasingly, scholars like Fleming, Kubota (2015), Lee (2015) and Larsen-Freeman (2018) are calling for transparent recognition of this type of discrimination in Canada. Discrimination remains pervasive despite having shifted from historically explicit forms of exclusion based on race to current forms of exclusion based on culture or language. Thus, documents associated with language learning for newcomers reproduce social subjugation on a large scale. This makes these documents important objects of analysis for better understanding discrimination as a social problem in Canada. 


\section{Critical Discourse Analysis as Theory}

In research on immigrant identity, integration, language learning and "being Canadian," notions of dominant and minority are explicitly and implicitly embedded. Accordingly, a critical theoretical framework views minoritized individuals as having agency to negotiate and construct their identity and environment (Freire, 1970; Giroux, 1985). Within this, Critical Discourse Analysis (CDA) plays a crucial role in understanding power and agency in language and text. Discourse analysis views language as an integral analytic lens for social practices and semiosis. It is concerned with how a text (form) explains what it is doing (function), and how this reproduces the "social, political, cultural, and institutional worlds" (Gee, 2004, p. 48) in which social actors interact. Discourse is constitutive and constituted because it both shapes and reflects social structures (Luke, 1996). In this way, discourse analysis "oscillates between a focus on structure and a focus on action" (Fairclough, 2001, p. 124). It explores the relationship between concrete microlevel discourses and structural macro-level ideologies (Fairclough, 2010).

CDA reveals ideology by analyzing power behind discourse (Fairclough, 2001). Language embeds power relations that underlie larger social problems like the one described above (Rogers, 2004). By enlisting the concept of hegemony "to theorize the subjugation of one social group to social groups" (Jorgensen \& Philips, 2002, p. 57), CDA reveals how discourses within cultural structures, relations and practices impact socially oppressed groups. CDA is ultimately committed to social change and emancipation.

With this theoretical basis, my analysis seeks to explore how LINC materials shape or are shaped by ideological structures that contribute to continued discrimination and othering of immigrants in Canada. Taking the side of new immigrants, my analysis yields implications for LINC teachers and classrooms towards greater equity for newcomers in and beyond language classrooms.

\section{Critical Discourse Analysis as Methodology}

This article looks at a unit of lesson plans used in LINC classroom settings, and asks: how do LINC lesson plans advance an understanding of integration (or assimilation) in Canada for classroom stakeholders (Canadian teacher and immigrant students)? This question is explored through analysis of a teaching resource called LINC Classroom Activities (Geraci et al., 2010). The resource was designed based on LINC curriculum guidelines and the Canadian Language Benchmarks. The document itself was a project developed under the Toronto Catholic District School Board and funded by Immigration, Refugees and Citizenship Canada. It is available online free of cost as a resource for LINC centers and teachers. The coursebook is organized into thematic units, each with a series of lesson plans and recommended assessment tasks. This analysis focuses on the unit called Social Interaction (p. 359-380) for the highest-level learners. The unit aims to develop advanced language skills for social interaction among Canadians. Lesson titles include Using Diplomatic Language and Being Assertive.

Fairclough (2003) reminds us that discourse analysis is a form of social analysis. It recognizes ways that language use (through both written or spoken texts) reflects social structuring. Thus, examining the structure, order and patterns within texts enables an understanding of how texts represent the social world, and from what perspective. A text 
refers to language in either written or spoken form. Fairclough suggests that CDA should oscillate between a focus on the text and on the social structuring they exist within, (re)produce, and/or seek to change. CDA occurs through detailed and repeated reading of a text "up and down across different levels and back and forth from smaller to larger units" (Wood \& Kroger, 2000, p. 94) until patterns emerge and a set of claims can be proposed with reasonable justification and support. Throughout this article, when I refer to "the text" I am referring to the Social Interaction unit under analysis.

In this analysis of the Social Interaction unit for immigrant language learners, I make use of Fairclough's (2003) three analytical categories: genre, discourse and style. Genre is a "way of acting and interacting linguistically" (Fairclough, 2003, p. 17). Distinct genres, such as an interview or a lecture, have particular ways of structuring language. The genre dictates grammatical relations, the type of exchange, the function of the language, and grammatical mood. Although genre can be theorized at a high level of abstraction (i.e., argument, narrative), to analyze genres in more specific concrete contexts, Fairclough uses the terms disembedded genre (a genre that is "lifted out" of its initial context and that now transcends different contexts) and situated genres (a genre specific to actors within a particular context). Genres can be complex, overlapping, and creatively used. In the text analyzed in this article, the abstract genre is lesson plan or teacher guide. Yet, closer analysis reveals a disembedded genre of How-to guide, which implicates the situated ways of acting and interacting in the unique Canadian context when considering the text's use in supporting Canadian citizenship and nationhood. Genre is analyzed in terms of its communicative or strategic purpose, its generic predictable structure, the way it structures social hierarchies or social distance and the mode of communication (one- or two-way; whether it is mediated).

Discourse "is a particular way of representing some part of the (physical, social, and psychological) world." (Fairclough, 2003, p. 17). Discourses offer different perspectives on the world depending on their position in the world. Different discourses provide conflicting representations of social relationships, social actors, and the history of events, including omissions or inclusions (p. 17). Discourses are identified through repetition, commonality, stability over time and being shared by many. In this analysis, discourses include multiculturalism, diversity, harmony, and Canadianness. These discourses have persisted throughout Canada's history and through changes in political leadership, although the way they are understood or articulated has varied (Gulliver, 2018; Joyce, 2014).

Styles are forms of identification played out based on social position, such as class, gender, or nationality. Fairclough identifies a tension between style as ascribed (being involuntarily pre-positioned or "identified") and agentive (recognizing that people can change and create their social world or "identifying"). Thus, while "characters", such as manager or politician, are a type of style, there are distinct styles of performing these characters depending on personality. In texts, styles are characterized by phonological features, vocabulary, and body language that carry messages about one's social identity. The styles in the text analyzed in this article include Canadian teachers and immigrant students. These are inherently hierarchicalized roles in that the teacher is both part of the dominant culture and holds a position of power in the classroom. Yet, agency in styles depends on the context of an event, the surrounding social relations, and the capacities of the agent (Fairclough, 2003). 
Genre, discourse and style are distinct but dialectically interconnected analytical categories. My analysis unpicks the mixed characteristics among the above categories to reveal the text's interdiscursive qualities. Interdiscursive analysis involves seeing texts in terms of the different discourses, genres and styles they draw upon and articulate together. On one hand, the Social Interaction text advances popular multicultural discourses of "harmony through diversity" through the genre of a lesson plans delivered in the style of a language lesson, invoking the roles of teacher and learner. At the same time, discursive notions of the "problematic Other" are introduced through a disembedded "how-to guide" genre that offers solutions delivered in the style of an authoritative government-funded document, invoking the roles of Canadian teachers helping deficient immigrant learners. I will justify and illustrate these claims using examples from the text to demonstrate ways that the text, through style, lexis and grammar, informs broader social structuring. Page numbers are provided to identify the location of examples in the text by Geraci et al. (2010). The critical discourse analysis that follows reveals strong links between English language teaching in Canada and assimilation, rather than integration, of immigrants to Canada. The text dictates ways that immigrants should change their ways of speaking and (inter)acting to "become more Canadian".

\section{Critical Discourse Analysis of LINC Classroom Activities}

\section{Genre: A How-to Guide for New Canadians}

In the broadest sense, the genre of the text is "lesson plan". In the Social Interactions unit, the lessons are focused on the pragmatics of English language use. The lessons diverge from the typical morphosyntax, lexis and phonology of language lessons, and attempts to enable learners to "know how-to-say-what-to-whom-when" (Culpeper et al., 2018). The focus on pragmatics is evidenced through ongoing guidance about how to "soften our statements" (p. 363) and use "careful language" (p. 366) or "appropriate language" (p. 367). That the document does little to address grammatical form for complex structures implies that the anticipated learner should already have mastery over these structures. This reflects a similar finding to Fleming's (2015): only the most proficient learners can access pragmatics lessons.

Since genres structure texts in specific ways (Fairclough, 2003), the lesson plan genre can be seen to give the text an inherent authority in the way that "truth" can be stated and defined rather explicitly. A set of values or Canadian ways-of-speaking are presented as facts for a group of learners likely coming from largely teacher-fronted learning backgrounds, leaving little room for questioning or presentation of alternative ways of interacting. Typical of the lesson plan genre, the text administers authority through the use of like the present simple used to state general permanent truths (e.g., "Assertive communication focuses on accurate statements of fact," p. 370; "Giving and receiving criticism in a constructive way involves focusing on facts and specific observations...," $p$. 372 ), the pronoun "you" to position the learner as the recipient of information (e.g., "You can encourage communication by indicating verbally and non-verbally that you are interested in what the other person is saying," p. 375; "By clarifying instructions, you can avoid misunderstandings," p. 377), and the future conditional functioning as a promise about what the learner will accomplish through the unit (e.g., this lesson "will help you..." 
p. 361). The grammatical mood is imperative, directing learner behaviours and tasks (e.g., "Avoid using negative adjectives," p. 363; "Use 'I' statements and avoid generalizations," p. 371).

Most lessons feature clear introductory statements where terms are defined authoritatively, as in the following examples: "Diplomacy refers to..." (p. 363); "Being assertive means..." (p. 370); "Handling criticism assertively involves..." (p. 372). Such statements assume that diplomacy, being assertive, and handling criticism are universally approached the same way by Canadians. They also assume a willingness on the part of newcomers to conform to the sociocultural linguistic practices in Canada. They fail to consider that teaching immigrant learners about Canadian ways of acting and interacting not only invalidates immigrants' own cultural ways of speaking but could also be disharmonious with their own lived experience using language in Canadian society (Guo, 2009). Rather than providing generalized definitions of language use in Canada, the Social Interactions unit could cultivate an "enriching awareness of both the differences and similarities among cultures and languages" (Joshee, 2009, p. 103) through a pedagogical approach that recognizes multiple perspectives. The unit could preface these definitions with statements that recognize the non-universality of these concepts while engaging learners in a discussion of their own experiences using language in their home country, as well as in Canada. For example, rather than beginning with an implicit assumption that Canada has a universal approach to diplomacy, lessons could start by discussing compatibilities, inconsistencies or opportunities for multiple modes of language use in the Canadian context. For instance, posing questions like, "What does diplomacy mean to you?" or "In your own language and culture, is it considered a positive thing to be assertive?"

Consideration of the lesson plan genre also reveals how the sequencing of each lesson informs the intended context in which language structures should be used. Lesson plans or sequences have different shapes and structures depending on the learning goal. Lesson shapes typically involve activating a learner's schemata, presenting a meaningful context for language use, then giving learners the opportunity to use the target structure in a guided then freer way. For instance, some lesson shapes follow a path from presentation to practice to production. The lesson shape featured in this text is task-based learning: learners are given a task where they notice a gap in their language ability, which is then filled through presentation of a language objective and then consolidated through further practice (Ellis, 2009). By identifying lessons where learners are presented with a language structure, and then noticing how the preceding task is used to contextualize the structure, a curricular design bias is revealed. I have highlighted the two clearest examples of this pattern in lesson shape in Figure 1. 
Figure 1

Lesson sequences reveal contexts for language use

\begin{tabular}{|c|}
\hline Interactional Styles at Work \\
\hline Using Diplomatic Language \\
\hline Writing Diplomatic Email Messages: Putting It in Practice............................ \\
\hline 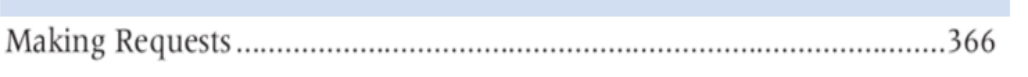 \\
\hline 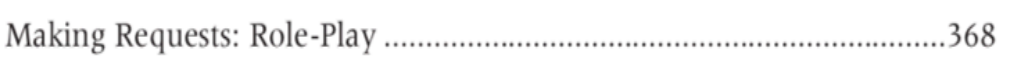 \\
\hline Responding to Inappropriate Questions and Comments...........................369 \\
\hline 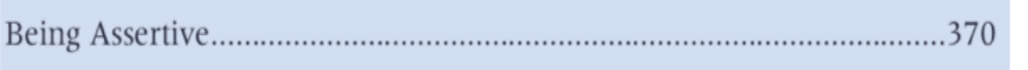 \\
\hline Being Assertive: Giving and Handling Criticism ........................................372 \\
\hline
\end{tabular}

In the first case, the target structure is "Using Diplomatic Language" (p. 363) and the preceding task is "Interactional Styles at Work" (p.362), where learners are guided to read examples of different interactional styles and consider how interaction style would impact job satisfaction and career advancement. Learners are then taught four strategies to use diplomacy so that "good relationships are maintained and there are no (or few) bad feelings" (p. 363). In so doing, a direct link is made between career success and satisfaction and using diplomatic language in interaction. Learners are taught to remain passively diplomatic in work-contexts in order to maintain workplace satisfaction. Later, "Being Assertive" (p. 370) is the target structure couched within lessons about "Responding to Inappropriate Questions and Comments" (p. 369) and "Giving and Handling Criticism" (p. 372). While the workplace $i s$ featured in these lessons, learners are also presented with a broader range of scenarios, including attending a baby shower, managing responsibilities and personal events outside of work (e.g., planning a wedding, dealing with a landlord, inlaws, and babysitters), driving, and even considering how to react when "another customer jumps in ahead of you" in line at the bakery (p. 370). The text asks learners to be assertive in response to discrimination, such as when a "co-worker makes fun of your accent" or "You ask a bus driver for directions. He mumbles something that you can't understand and you ask him to repeat. He says, 'Are you deaf?" (p. 370). These examples imply that learners will face discrimination and that it is their responsibility to know how to handle it. The context for language use points to a broader systemic issue of racism in Canada. The text is neither positioned to address this systemic issue nor does it target the correct audience. However, the text fails to explicitly address the systemic issue in Canadian society, and it responsibilizes immigrant learners to equip themselves with tools to stave off racism when they encounter it. The text should more explicitly address the systemic inequalities that it implicitly promises learners will encounter. Briefly, these two sequences of lessons imply there are certain contexts for diplomacy or assertiveness: by and large, being diplomatic is for the workplace, whereas being assertive applies to diverse personal contexts, particularly when discrimination is involved. These clues about the contextual use of language show how curricular designers implicitly suggest how and when immigrant learners should use language.

From a critical perspective, "pragmatic competence is a hybrid system reflecting multiple languages, communities and competencies" (Taguchi \& Rover, 2017, p. 275). 
Increasingly, critical second language acquisition research views other languages (and by extension, other pragmatics) as complex and emergent in conjunction with diverse contexts and resourceful innovative ways of using language (Kramsch, 2012; Larsen-Freeman, 2012, 2018). The question then arises: Whose pragmatics are being taught? Whose way of using language in whose context? In this text, an "ideal Canadian" form of pragmatics emerges through an unexpected intruding how-to guide genre. Lexis and stylization that indicate this genre include:

- "Constructive criticism follows three key steps" (p. 372)

- "Here are some more tips for giving feedback..." (p. 373)

- Advice for speaking style is given as a "dos and don 'ts" list (p. 377)

- Advice given in ways characteristic of an online blog, such as "Try to..." (375) Or "It's always a good idea to..." (377)

These examples reveal the text's didactic inclination to recommend to learners how to be, and how to behave through language use. The how-to guide genre reinforces a view of the learner's experience as deficient while the lesson plan genre implicitly advances a "Canadian" way of being. This hybrid genre sets the context for the mix of discourses within the text. Fairclough (2003) suggests that genre reveals the presumed patterns of social relations, the manner of communication, and the intended purpose of the text. In this case, the genre establishes social hierarchy and social distance between creator (designer) and beneficiary (immigrant learner). Since the text was funded by the federal government of Canada, it reflects an authoritative source and dominant perspective. The manner of communication is one-way and largely non-mediated, aside from the varying ways that teachers interpret and deliver the lessons. This Canadian English language pragmatics lesson plan how-to guide hybrid is purposed to share Canadian ways of speaking and interacting with newcomers "who are constructed as potentially lacking in the positive values" (Gulliver, 2018, p. 75). This negative presentation of the other is conveyed and constructed iteratively in the overlapping discourses further discussed below.

\section{Discourses of Canadianness: From Diversity to the Problematic Other}

A short "culture note" appears at the beginning of each unit. No rationale is provided for these "culture notes", nor is the source of their authorship cited. The culture note in this unit (p. 251, Figure 2) introduces dominant discursive themes that recur in the sequence of the lessons that follow. 
Figure 2

Culture Note with highlighted discursive themes

\section{Culture Note}

Canadian workplaces are diverse, not only because employees are from many different cultural backgrounds, but also because, regardless of their culture, they can have vastly different communication styles and life experiences. These differences can sometimes lead to misunderstandings.

It is important to be aware that your way of communicating and your perceptions can differ from those of others. Keeping an open mind, being flexible and tolerant of differences, and not generalizing about others will help you get along well in a diverse workplace. In addition, learning about your co-workers' cultural backgrounds will help you avoid miscommunication and contribute to your success at work.

I have added colours to show the interaction between overlapping discursive themes. Broadly, these themes interact as follows: difference and diversity (blue) are pervasive in Canada. Within this diversity, there is a particularly harmonious or peaceful way of behaving that is equated to being Canadian (red). This ideal Canadian way of being is contrasted to "your" ways of being (yellow). This culture note does the critical task of labelling the consumer of this material - the learner - using the possessive pronoun (your) to distinguish LINC learners from other Canadians. The use of pronouns you/your reflects a political linguistic strategy that Fairclough (2001) calls synthetic personalization, in which "relational and subjective qualities are exploited for institutional ends" (p. 2). In this case, for the purpose identified in the above analysis of genre: educating an "unknowing" group about being Canadian while maintaining a social hierarchy in distinguishing LINC learners from other Canadians. These groups are further distanced discursively by the creation of a gap between the learner and the ideal Canadian. This gap exists due to the possibility of misunderstanding or miscommunication (green) that stems from their differing forms of communication. Although this excerpt initially divorces cultural background from miscommunication, it reiterates the causal relationship in the final sentence. This puts the onus on the learner to avoid miscommunication, while also justifying the purpose of the unit as the solution to the problem.

In what follows, I will unpack how these four discursive themes interact: difference and diversity, Canadian harmony, opposing "LINC learner" styles of speaking that challenge Canadian harmony, and the alleged resulting miscommunication. Fairclough (2003) states that discourses offer "perspectives on the world, and they are associated with different relations people have to the world" (p. 124). Therefore, this analysis identifies how the world is represented and from which perspective, pointing to vocabulary, semantic relations and grammatical features that iteratively generate a dominant (white) Canadian perspective of the world.

Historically, Canada has celebrated diversity and difference, which is promoted in this sequence of lessons. However, throughout the text, difference and diversity are plainly linked to culture. Excerpts that illustrate this include: "Some of these differences are due to cultural factors" (p. 362) and "using appropriate language for making requests requires some awareness of the differences in cultural norms" (p. 366). The text positions language as the solution for understanding cultural differences, associating a particular way of using English with Canadian culture. This is most clearly reflected in the lesson called "Confirming and Clarifying Instructions" (p. 377). In this lesson, students are asked to 
complete a role play in pairs, where one student plays a manager and the other plays an assistant. The assistant is required to clarify and confirm instructions - and students take turns playing the assistant role. Instructions to the student playing the assistant are worded: "As the assistant you must use strategies to clarify and confirm the instructions" (p. 377, emphasis added). That the assistant - and not the manager - would be responsible for miscommunication is representative of a broader theme running throughout: those with less power are responsible for miscommunication. The "assistant" or the language learner, rather than the "manager" or native speaker interlocutor are responsibilized to reduce the likelihood of miscommunication.

This type of responsibilization calls into question the broader discourse of integration as a two-way process. Throughout the Social Interactions unit, the immigrant language learner is guided to take responsibility to avoid miscommunication with other Canadians. This is established in the culture note at the start of the unit: "It is important to be aware that your way of communicating and your perceptions can differ from those of others.... Learning about your co-workers' cultural backgrounds will help you avoid miscommunication...." (Geraci et al., p. 251). This is re-established in the "Making Requests" lesson where learners read, "Using the appropriate language for making requests requires some sensitivity to other person's personality and some awareness of the differences in cultural norms" (p. 366). This phrase implies learners need to adapt their ways of making requests, taking care to notice the cultural gap between themselves and others. Another example is in the "Being Assertive" lesson, in which learners see that they can be assertive "in a way that is honest, direct and respectful of the rights and feelings of others" (p. 370). Although this lesson importantly works to develop a sense of immigrants being able to express their own "needs, feelings and views," this can only be done in the context of first being sensitive to others. The text hints at reciprocity and respect between people, yet throughout the lessons, immigrant language learners are not exposed to the other side of this relationship. The unit puts responsibility entirely on immigrants to adapt their ways of speaking to respectfully interact with others, rarely acknowledging that there may be "other Canadians" who do nothing to interact respectfully with new Canadians. Regardless of how other Canadian interlocutors behave, the learners of this unit are taught to remain calm, passive, and maintain peaceful good relationships. Two-way integration amounts to idealism in this text, which calls on learners to distance themselves from their own cultural background and move towards being Canadian. The text casts diversity as problematic to Canadian harmony, and assimilation is held as the solution.

\section{LINC Teachers as Canadian Cultural Guides}

Assimilation is promoted throughout the text by encouraging the embodying and enacting of a Canadian way of being. This is presented through discursive patterns of politeness, diplomacy and harmony. The following are identified as "targets" for the learner: "Foster and maintain good relationships" or "Improved relationships" (p. 363, 372); Ensuring there are "no (or few) bad feelings" (p. 363); "Polite and careful language" (p. 366); "Remaining calm" and "calmly disagreeing" (p. 372); "Encouraging communication" (p. 375); "Respecting the views of others" (p. 378). This focus on relationships and language use throughout the unit assumes multiple intersecting "styles" in the classroom. 
The styles, or modes of identification, in this text are most abstractly categorized as drawing on two characters: language teacher and language learner. Fairclough (2003) notes that different personalities have a way of investing in the characters they play. In these texts, the LINC teacher may additionally identify as a mentor, Canadian expert or cultural guide. In each lesson, the first person is used: "the words we choose when making requests..." (p. 366) and "awareness that our judgements are..." (p. 363). First person is most commonly used in narrative writing to build the identity of the author or speaker. It develops character while setting a clear perspective and aligning the narrator as the protagonist (Sundberg, 2011). To contrast, the learner is addressed with the second person pronoun (you), and through the imperative form (e.g., "Underline examples of..." on page 363; "Discuss the following" and "Listen to an excerpt" on page 369). This is established in the binary use of pronouns throughout the text. The binary between "we" Canadians and "you" immigrants marks a distinction and distance between Canadian teachers as in-group and immigrant learners as out-group (van Dijk, 1989). The imperative form, albeit characteristic of the lesson plan genre, functions to give instructions or make commands and orders. Taken together, these features of the text imply the teacher is part of the Canadian in-group that possesses the "correct" way of using language and interacting in contrast to the inferior learner, who receives instruction to minimize their deficits. The text could rid itself of this ideological binary and deficit thinking by adopting a view that the learner is involved in the construction of language use and interaction norms. This accompanies a view that learning is emergent and dynamic, rather than fixed and deterministic since learners have a capacity to "actively transform their linguistic world... not merely conform to it" (Larsen-Freeman, 2012, p. 306). Rather than frame the text as a passing of information from knowing "we" to an unknowing "you", the text should nurture critical consciousness that enables immigrant learners to explore the relationship between language and power so that they can see how English is used to maintain control (Guo, 2009). This could occur through acknowledgement and validation of other ways of speaking and interacting. Such an acknowledgment should take the form of a preface that explicitly states bias and recognizes dominance; validation should occur by question posing, where learners are invited to share their experiences and perspectives on other ways of speaking and interacting.

\section{Discussion: Dominant Ideology \& Possibilities for Resistance and Change}

I have argued that the hybrid genre of this text sets the context for inferiorization of immigrant learners, reinforced through discourses that position newcomers as deficient. This is further solidified by the roles social actors play in the classrooms that call not only on their identities in classrooms as teachers and learners, but on their whole beings as insiders or outsiders in the wider context. I have sought to "establish through critique that the social order inherently generates a range of major problems which it "needs" in order to sustain itself" (Fairclough, 2001, p. 126). These problems comprise positioning the immigrant learners' ways of speaking and interacting as inferior to a preferred Canadian standard of language use. I have shown how discursive patterns of self and Other contribute to an ideology that sustains relations of power and domination in the favour of an English-speaking Canadian pragmatics. This domination requires newcomers to strive to 
assimilate in order not to be considered a problem or impediment to harmony in their new Canadian home.

Critical discourse analysis also involves finding exceptions: "showing contradictions or gaps or failures within the domination in the social order" and "showing difference and resistance" (Fairclough, 2001, p. 126). Some such resistance appears in the lesson titled "Responding to Inappropriate Questions and Comments". In a listening task, learners are presented with the story of a racialized Canadian woman who was offended when an interlocutor questioned her fluency in English. The story is quickly dismissed as an amusing anecdote and learners are only asked to retell the story (a comprehension task) with no further discussion. Although this specific story may not be relatable for all LINC learners, the story touches on the important issue of discrimination in relation to race, nationality and language. Potentially, this lesson could create space for further discussion regarding challenges faced by Canadian immigrants, particularly as language learners. The lesson mentions other possible immigrant experiences like being chastised for an accent or marginalized for asking that something be repeated (p. 371). Although largely dependent on the particular classrooms where different teachers and learners interact with this lesson, it could potentially validate language learners' lived experiences and develop communication and understanding at the micro (classroom) level. Content that focuses on discourses of "otherness" from a problematizing perspective may transform the classroom space into one of meaningful interaction. This might be very important to immigrant learners if they consider the LINC classroom as a site of support and allyship between themselves and other Canadians. This alternative discursive theme could call into play the multiple styles of interactants. With careful and thoughtful attention, classroom stakeholders could create space for resistance, and thus, emancipation and potential sociocultural change.

\section{Implications: Critical Language Awareness \& Emancipation}

This analysis revealed how language dictates social practices through LINC teaching activities. I will conclude by suggesting implications for stakeholders (teachers, students, lesson designers) in LINC curriculum design, lesson preparation and lesson dissemination.

Jorgensen \& Philips (2002) highlight critical language awareness as an important aspect of helping social actors become more aware of the "constraints on their practice and possibilities for resistance and change" (p. 77). LINC lesson designers and teachers should become aware of how formal qualities of language impact inclusion and exclusion. For instance, noticing how pronouns can sweepingly categorize individuals as either part of the in-group or out-group, or attending to how grammatical structures like imperatives implicate a direct power differential between interactants. Teachers encountering these structures in their classrooms should consider inclusive alternatives, or at least address them openly to expose their effect or hidden functions.

In terms of the discourses established in the unit, LINC lesson designers should critically consider how topics and learning outcomes are framed and structured at a unitlevel to ensure an appropriate balance of language use in diverse contexts. For instance, rather than associating diplomacy predominantly with the workplace, learners could be guided to consider areas of their own lives where diplomacy would be important - and 
contexts where it may not be. Also, reconsidering who is responsible for communication and blamed for miscommunication is crucial for any English language classroom. This requires acknowledging a more systemic problem in Canada. In this text, diversity discourses are frequently linked to deficit ideology. It is critical that texts like this be rewritten from a perspective that considers diversity as a valuable resource in the classroom and beyond. Such a text would recognize and explicitly state bias and power dynamics, then work to acknowledge and validate other ways of speaking and interacting.

In my argument that the text discursively promotes a one-direction approach to integration where immigrants are responsibilized for the success of their communication with Canadian interlocutors, I have problematized the manner in which information is presented in the text. Nevertheless, some of the guidance provided in the text, such as the advice to maintain good relationships, use polite language or disagree calmly, are important aspects of communication that may very well help marginalized groups manage their relationships in their new home. I do not intend to imply that this information is entirely unhelpful. Rather, I am suggesting that the way it is presented as the Canadian way of interacting occurs at the expense of immigrants' own lived experiences and understandings. Thus, a question arises: how can LINC teachers reconcile empowerment and oppression when teaching newcomers ways of speaking and interacting in Canada? As I have suggested throughout, teachers should work toward acknowledging dominant bias, and then recognize and validate other ways of speaking and interacting. When language teachers operate from a pedagogical perspective that acknowledges the emergent nature of knowledge and language (e.g., an ecological perspective of language learning, translanguaging pedagogy, viewing language as a complex dynamic system), the language classroom is transformed into a more equitable and diverse space. Unfortunately, there are limitations to the reach of language classrooms. Block (2018) argues that new research in classrooms that validates other cultures and languages cannot "convince the dominant class to respect working-class dialects and not vilify and denigrate them" (p. 253). Block argues that what is needed to impact change beyond classrooms is a fundamental change in the economy's organization. Similarly, Haque (2017) notes that as subjects of language training policy, teachers, and learners are never outside of techniques of power even as they work toward bringing their own understanding of policy and improve the lives of newcomers in Canada.

LINC teachers are critical points of contact for newcomers to Canada. Thus, this analysis supports the need for them to become aware of the widespread discrimination and racism that exists in Canada. If LINC teachers were more aware of this, their role could shift from non-critical language teacher as a passive conduit of "Canadian pragmatics", to a more holistic and relational role as ally to newcomers. In this way, the LINC curriculum and classroom can become a locus for societal change towards more equitable relations between all Canadians. Moreover, this shift in role and focus may reduce the extent that newcomers are expected to assimilate, and chart the course for integration between equally responsible interlocutors.

\section{Conclusion}

Using an authority inherent to an ESL lesson plan, the analyzed text exploits its power by teaching immigrants a specific way of being and using language. The invading genre of a how-to guide, when delivered by Canadian teachers, positions immigrant 
"others" as relatively powerless in binary relation to Canadians. The text encourages assimilation through ways of using language to avoid miscommunication, which is a barrier to the characteristically harmonious way of being and living in Canada. This directly opposes wider discourses of integration in Canada as newcomers face a one-way process of assimilation.

Critical discourse analysis has enabled a careful reading of this text such that discourses fueling these hegemonies have been illuminated. For teachers and lesson designers, critical language awareness is required to reveal how power within language contributes to hegemony. In this way, LINC stakeholders can create space for resistance and change in the LINC program (for the production of future documents) and in LINC classrooms (for critical consumption of existing documents).

Correspondence should be addressed to Marianne Barker.

Email: marianne.barker@mail.mcgill.ca

\section{References}

ARCHIVED - backgrounder - language instruction for newcomers to Canada (LINC) program. (2013). https://www.canada.ca/en/immigration-refugeescitizenship/news/archives/backgrounders-2013/language-instruction-newcomerscanada-linc-program.html

Augoustinos, M., \& Every, D. (2010). Accusations and denials of racism: Managing moral accountability in public discourse. Discourse and Society, 21(3), 251-256. http://doi.org/10.1177/0957926509360650

Block, D. (2018). The political economy of language education research (or the lack thereof): Nancy Fraser and the case of translanguaging. Critical Inquiry in Language Studies, 15(4), 237-257.

Bloemraad, I. (2016). Understanding "Canadian exceptionalism” in immigration and pluralism policy. Migration Policy Institute

Cardozo, A., \& Pendakur, R. (2008). Canada's visible minority population: 1967-2017. Metropolis British Columbia.

Chun, C.W. (2016). Addressing racialized multicultural discourses in an EAP textbook: Working toward a critical pedagogies approach. TESOL Quarterly, 50(1), 109-131.

Culpeper, J., Mackey, A., \& Taguchi, N. (2018). Second language pragmatics: From theory to research. Routledge.

Day, R. J. F. (2000). Multiculturalism and the history of Canadian diversity. University of Toronto Press.

Ellis, R. (2009). The methodology of task-based teaching. Paper presented at the Cebu Conference, Philippines.

Fairclough, N. (2001). Language and power (2nd ed.). Pearson Education.

Fairclough, N. (2003). Analyzing discourse: Textual analysis for social research. Routledge.

Fairclough, N. (2010). Critical discourse analysis: The critical study of language (2nd ed.). Routledge.

Fleming, D. (2015). Citizenship and race in second-language education. Journal of Multilingual and Multicultural Development, 36(1), 42-52.

Freire, P. (1970). Pedagogy of the oppressed. Herder and Herder. 
Gee, J. P. (2004). Discourse analysis: What makes it critical? In R. Rogers (Ed.), An introduction to critical discourse analysis in education (pp. 19-50). Lawrence Erlbaum Associates.

Geraci, K., Hajer, A., Kaskens, A.M., \& Stasiak, M. (2010). LINC 5-7: Classroom activities (Vol. 1). Toronto, Canada. http://www.moresettlement.org/LINC57Activities/LINC_5-7_Classroom_Activities_Volume1.pdf

Gibb, T. L. (2009). Bridging Canadian second language education and essential skills policies: Approach with caution. Adult Education Quarterly, 58(4), 318-334.

Giroux, H. (1985). Critical pedagogy, cultural politics and the discourse of experience. Journal of Education, 167(2), 22-41.

Gulliver, T. (2018). Canada the redeemer and denials of racism. Critical Discourse Studies, 15(1), 68-86. http://doi.org/10.1080/17405904.2017.1360192

Gulliver, T., \& Thurrell, K. (2016). Denials of racism in Canadian English language textbooks. TESOL Canada Journal, 33(10), 42-61. http://doi.org/1018806/tesl.v33i0.1244

Guo, Y. (2009). Racializing immigrant professionals in an employment preparation ESL program. Cultural and Pedagogical Inquiry, 1(1), 40-54.

Guo, Y. (2013). English as a Second Language (ESL) Programs for Adult Immigrants in Canada: Critical issues and perspectives. In T. Nesbit, S. M. Brigham, N. Taber, \& T. Gibb (Eds.), Building on critical traditions: Adult education and learning in Canada (pp. 330-341). Thompson Educational Publishing.

Guo, Y. (2015). Language policies and programs for adult immigrants in Canada: Deconstructing discourses of integration. New Directions for Adult and Continuing Education, 146, 41-51.

Haque, E. (2012). Multiculturalism within a bilingual framework: Language, race, and belonging in Canada. University of Toronto Press.

Haque, E. (2017). Neoliberal governmentality and Canadian migrant language training policies. Societies and Education, 15(1), 96-113.

IRC Canada. (2017). 2017 Annual report to parliament on immigration. Ahmed D. Hussen, Minister of Immigration, Refugees and Citizenship.

Jorgensen, M. W., \& Philips, L. (2002). Discourse analysis as theory and method. SAGE Publications Ltd.

Joshee, R. (2009). Multicultural education policy in Canada: Competing ideologies, interconnected discourses. In J.A. Banks (Ed.), The Routledge international companion to multicultural education (pp. 96-108). Routledge.

Joyce, C. (2014). From "peaceable kingdom" to "warrior nation": A comparative analysis of the liberal and conservative citizenship study guides. CAPSTONE SEMINAR SERIES (Re)Negotiating Artefacts of Canadians Narratives of Identity, 4(1), 1-18.

Kramsch, C. (2012). Why is everyone so excited about complexity theory in applied linguistics? Melanges CRAPEL (33), 9-24.

Kubota, R. (2015). Race and language learning in multicultural Canada: Towards critical antiracism. Journal of Multilingual and Multicultural Development, 36(1), 3-12.

Kurl, S. (2016). What makes us Canadian? A study of values, beliefs, priorities and identity. Angus Reid Institute, Public Interest Research.

Larsen-Freeman, D. (2012). The emancipation of the language learner. Studies in Second Language Learning and Teaching, 2(3), 297-309. 
Larsen-Freeman, D. (2018). Second language acquisition, WE, and language as a complex adaptive system (CAS). World Englishes, 37, 80-92.

Lee, E. (2015). Doing culture, doing race: Everyday discourses of 'culture' and 'cultural difference' in the English as a second language classroom. Journal of Multilingual and Multicultural Development, 36, 90-93.

Li, P. (2003). Deconstructing Canada's discourse of immigrant integration. Journal of International Migration and Integration, 4(3), 315-333.

Luke, A. (1996). Text and discourse in education: An introduction to critical discourse analysis. Review of Research in Education, 21, 3-48.

Pashby, K., Ingram, L.-A., \& Joshee, R. (2014). Discovering, recovering, and covering-up Canada: Tracing historical citizenship discourses in K-12 and adult immigrant citizenship education. Canadian Journal of Education, 37(2), 1-26.

Ricento, T., Cervatiuc, A., MacMillan, F., \& Masoodi, S. (2008). Insights into funded ESL programs: Report on the LINC program. University of Calgary, Canada.

Rogers, R. (2004). An introduction to critical discourse analysis in education. Mahwah, New Jersey: Lawrence Erlbaum Associates, Publishers.

Sundberg, I. (2011). Five reasons to write in the first person point-of-view. http://ingridsundberg.com/2011/03/14/five-reasons-to-write-in-the-first-personpoint-of-view/

Taguchi, N., \& Rover, C. (2017). Second language pragmatics. Oxford University Press. van Dijk, T.A. (1989). Mediating racism: The role of media in the reproduction of racism. In R. Wodak (Ed.), Language, power and ideology: Studies in political discourse. John Benjamins Publishing Company.

van Dijk, T.A. (1992). Discourse and the denial of racism. Discourse and Society, 3(1), 87118.

Wood, L. A., \& Kroger, R. O. (2000). Doing discourse analysis: Methods for studying action in talk and text. Sage Publications Ltd. 